\title{
Haemostasis and Safety Measures before Lumbar Puncture in the Haematology Ward: The Danish Routines
}

\author{
Anders Møller ${ }^{a, b} \quad$ Ole Weis Bjerrum ${ }^{b} \quad$ Arash Afshari $^{c}$ \\ ${ }^{a}$ Department of Anaesthesia, Slagelse Sygehus, Slagelse, and ${ }^{\mathrm{b}}$ Department of Haematology, and ${ }^{\mathrm{c}}$ Department of \\ Anaesthesia, Juliane Marie Center, Copenhagen University Hospital (Rigshospitalet), Copenhagen, Denmark
}

For editorial comment see p. 106

\section{Key Words}

Anticoagulants - Lumbar puncture - Ophthalmoscopy .

Platelet aggregation inhibitors - Questionnaires .

Spinal epidural haematoma . Subdural haematoma .

Thrombocytopenia $\cdot$ Tonsillar herniation

\begin{abstract}
Background/Aims: Thrombocytopenia and the increasing use and variety of antithrombotic drugs is a challenge prior to lumbar puncture. This study examined the Danish haematology practice regarding drug pausation, assessment of haemostasis and whether fundoscopy is a routine safety measure. Methods: An online survey with questions pertaining to precautions of haemostasis and application of fundoscopy was sent by e-mail to all 12 haematology wards in Denmark. Results: Eleven sites participated. Five (45\%) reported no pausation of antiplatelet drugs at all. The mean platelet limit prior to lumbar puncture was $50 \times 10^{9} /$ I (range $10-50 \times$ $\left.10^{9} / \mathrm{l}\right)$. Seven (64\%) sites had an international normalised ratio limit of 1.5 , and the remaining 4 had values between 1.0 and 2.5. Two (18\%) reported occasional use of thromboelastography or platelet analysis to assess the bleeding risk. Fundoscopy is routinely performed in $4(36 \%)$ departments. Conclusion: We report considerable variation in the routine handling of antithrombotics and thrombocytopenia in pa-
\end{abstract}

tients set for lumbar puncture in Danish haematology departments. The diversity may be explained by and related to different opinions in the literature. Common national guidelines are warranted and there is a need for studies to establish an evidence-based approach for the management of patients at risk of bleeding when lumbar puncture or another invasive procedure is indicated.

(c) 2014 S. Karger AG, Basel

Across all medical disciplines, when performing lumbar dural puncture (LP), haemostatic management is increasingly a matter of concern due to a rising prevalence of antithrombotic therapy. In 2012, 9.6\% of all Danes received prophylaxis against thrombosis [1], and the treatment is administered with an increasing variety of drugs targeting platelets and different steps in the coagulation cascade. Additionally, even in the absence of prophylaxis, haematology patients may have an increased bleeding risk due to low platelet counts or abnormal platelet function.

In haematology, LP is used for therapeutic (i.e. administration of cytotoxic drugs) and diagnostic purposes (i.e. clarification of disease involvement in leukemia or lymphoma). A diagnostic LP can also be performed to demonstrate viral or bacterial meningitis, or complications

\section{KARGER 125}

C 2014 S. Karger AG, Base

$0001-5792 / 14 / 1331-0108 \$ 39.50 / 0$

E-Mail karger@karger.com

www.karger.com/aha
Anders Møller, MD

Department of Anaesthesia, Slagelse Sygehus

Ingemannsvej 18

DK-4200 Slagelse (Denmark)

E-Mail dr.andersm@gmail.com 
like Guillian-Barré syndrome, which immunosuppressed or neutropenic patients are predisposed to.

Complications following LP include post-dural puncture headache, back pain, neck stiffness, nausea, photophobia, hearing loss and other cranial nerve palsies [2]. Potentially life-threatening or debilitating complications like haematomas, incarceration and infections are rare [3, 4]. More recent guidelines have focused on the risk of spinal haematoma in spinal anaesthesia $[5,6]$, a feared sequel often associated with impaired haemostasis [4]. Once present, permanent paraplegia can ensue even after surgical decompression [4], and permanent deficits have been reported in up to $90 \%$ of cases [5]. The haematology population, in particular patients treated by haematopoietic stem cell transplantation, may be at an increased risk of developing cranial subdural haematoma $[7,8]$.

Arterial and venous thrombi are major causes of morbidity and mortality. Thus, performing LP in patients receiving antithrombotic drugs is complex, and the use of para-clinical assessment to predict the risk of bleeding remains a challenge because of the poor predictive value of the current tests $[9,10]$.

This study aimed to describe LP practice in a haematology context with regard to haemostatic safety measures and whether fundoscopy is routinely performed. We discuss the results of a survey in light of the current evidence and give an overview of the possible complications. Although the present article focuses on haematology wards in Denmark, it may very well prove useful for and give perspective to physicians in other specialties and internationally.

\section{Methods}

A survey was created electronically. It was disseminated to a senior colleague at each of the 12 haematology wards in Denmark in March 2012.

The questions referred to routine pausation of antithrombotic drugs, the choice of para-clinical tests to assess the bleeding risk and the application of fundoscopy.

All questions were multiple-choice, giving predefined intervals for the answers. Submission was not permitted without a $100 \%$ response rate.

\section{Results}

Data from 11 of the 12 invited sites were collected in April 2012 and the survey was closed for further access. One department declined to participate because LP is a rare procedure at that unit.

Safety Measures before Lumbar Puncture in Denmark

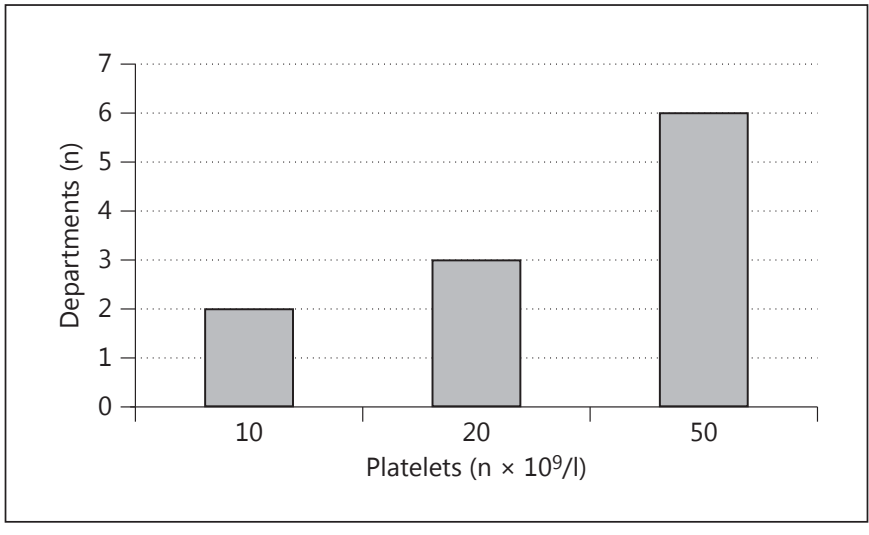

Fig. 1. Lowest acceptable limit of platelets on the day of lumbar puncture $\left(\times 10^{9} / 1\right)$.

The results are presented referring to the platelet count as the limit before LP (fig. 1) and the therapeutic precautions taken before LP (table 1).

Figure 1 shows a wide variation in the reported lowest acceptable limit for platelet counts on the day of LP (fig. 1). The results illustrate the limit at which a patient in that particular department would receive platelet transfusion before LP, when evaluated based on the platelet count. Our survey did not ask for the number of platelet transfusions given when the platelet count was below the acceptable limit prior to LP.

Table 1 presents the results of therapeutic precautions if patients on antithrombotic therapy were scheduled for LP. The results show a broad range with regard to the timing of vitamin $\mathrm{K}$ antagonists and platelet inhibitor cessation. Thromboelastography (TEG) and platelet function analysis (PFA) were not found to be common practice among Danish haematologists. Fundoscopy prior to LP was a routine procedure at less than half of the 11 departments.

\section{Discussion}

Our survey is the first national questionnaire in haematology in Denmark to collect data on a clinical procedure. The results show that the evaluation of haemostasis and safety measures, such as the platelet limit on the day of LP, cessation of antithrombotic therapy and performance of a fundoscopy, varies greatly as reflected by the controversies in the current literature described below.

Our search for 'an acceptable platelet count' was performed to gain knowledge about the 'critical limit' for when LP are performed and considered to be safe (fig. 1). 
Table 1. Haemostatic precautions and fundoscopy $(\mathrm{n}=11)$

\begin{tabular}{|c|c|}
\hline Question & $\mathrm{n}(\%)$ \\
\hline \multicolumn{2}{|l|}{ Pausation of LMWH prior to LP } \\
\hline $12-24 \mathrm{~h}$ depending on the dosage & $5(45)$ \\
\hline LMWH is not used in connection with LP & $0(0)$ \\
\hline \multicolumn{2}{|c|}{ Adhering to guidelines from the DSTH and/or with } \\
\hline \multicolumn{2}{|l|}{ Pausation with vitamin $\mathrm{K}$ antagonists prior to $\mathrm{LP}$} \\
\hline 1 day & $1(9)$ \\
\hline 2 days & $1(9)$ \\
\hline 3 days & $7(64)$ \\
\hline 4 days & $1(9)$ \\
\hline 5 days & $1(9)$ \\
\hline \multicolumn{2}{|l|}{ Maximal INR value on the day of sampling } \\
\hline 1.0 & $1(9)$ \\
\hline 1.2 & $1(9)$ \\
\hline 1.5 & $7(64)$ \\
\hline 2.0 & $1(9)$ \\
\hline 2.5 & $1(9)$ \\
\hline \multicolumn{2}{|c|}{ Routine pausation of platelet inhibitors ${ }^{1}$ (days not specified) } \\
\hline None & $5(45)$ \\
\hline Aspirin & $3(27)$ \\
\hline Persantine & $4(36)$ \\
\hline Asasantine & $4(36)$ \\
\hline Clopidogrel & $6(55)$ \\
\hline Other $^{2}$ & $1(9)$ \\
\hline \multicolumn{2}{|c|}{$\begin{array}{l}\text { Use of other para-clinical tests when in doubt about the risk of } \\
\text { bleeding }\end{array}$} \\
\hline Thromboelastography (e.g. TEG or ROTEM) & $2(18)$ \\
\hline Platelet analysis (e.g. Multiplate or PFA-100) & $1(9)$ \\
\hline No, never & $9(82)$ \\
\hline Not available at the department & $1(9)$ \\
\hline \multicolumn{2}{|l|}{ Routine fundoscopy prior to LP } \\
\hline Yes & $4(36)$ \\
\hline No & $7(64)$ \\
\hline \multicolumn{2}{|c|}{$\begin{array}{l}\text { The survey can be viewed at: dl.dropbox.com/u/456627/sur } \\
\text { vey.pdf. LMWH = Low-molecular-weight heparin; DSTH = Da } \\
\text { nish Society of Thrombosis and Haemostasis. } \\
{ }^{1} \text { Multiple selections allowed. }{ }^{2} \text { One department specifically } \\
\text { mentioned ticagrelor. }\end{array}$} \\
\hline
\end{tabular}

The results showed a 5 -fold range of platelet limits as the clinical guideline in the 11 departments. In 6 departments, platelets would be administered at a level below $50 \times 10^{9} / 1$, in 3 departments at $20 \times 10^{9} / 1$ or below and in 2 departments at $10 \times 10^{9} / 1$ (fig. 1 ). This demonstrates that the use of platelet transfusion varies considerably. LP can be carried out safely based solely on the platelet count and at levels as low as $40 \times 10^{9} / 1$ [6]. However, since the platelet count is not re-analysed routinely following 1 or 2 platelet transfusions, the risk of a haemorrhagic adverse event in individual patients is difficult to assess.
It was not the aim of this study to examine the frequency of complications following LP. Furthermore, we were unable to determine whether different attitudes towards the lowest acceptable platelet limit may yield differing safety profiles. This would require extensive data most likely exceeding several years of procedures with complete follow-up.

The risk of spinal haematoma following diagnostic LP remains to be determined. However, it has been extensively studied in anaesthetic procedures, with recent estimates of 1:100,000 after epidural labor analgesia and 1:3,600 in female orthopedic patients for epidural analgesia and 1:22,000 for spinal anaesthesia [5]. A sudden onset of intense, knife-like back pain should arouse suspicion [4]. The pain can be absent [5] or may be followed in some cases by a pain-free interval of minutes to days, after which there is progressive paralysis below the affected spinal level and/or sensory changes and incontinence [4]. Prompt magnetic resonance imaging is paramount, as a delay in diagnosis has been associated with a poor prognosis $[3,5,11]$. The treatment of choice is surgical decompression $[3,4]$.

Cranial subdural haematoma is a known complication of haematopoietic stem cell transplantation [7, 8], diagnostic LP [12] and spinal anaesthesia [13]. Diagnosis is complicated by the fact that the symptoms resemble those of post-dural puncture headache, viral meningitis, cortical vein thrombosis and sinus headache [12] and by the fact that an initial normal brain imaging may not necessarily rule out a cranial subdural haematoma. Repeated computed tomography has been shown to be necessary in haematology patients [7].

Moreover, it has been hypothesised that the pathogeneses of post-dural puncture headache and this spontaneous or 'non-traumatic' subdural haematoma are similar due to cerebrospinal fluid leakage from the puncture site [12]. Dural puncture may be the first link in a chain of adverse events ultimately leading to cranial subdural haematoma, which can be avoided by following a series of simple recommendations $[2,14]$. These include preventing post-dural puncture headache via the use of an atraumatic needle $[2,15]$ and treating the condition with an epidural blood patch [14].

Symptoms of cranial subdural haematoma include reduced consciousness, focal neurological signs and prolonged and prominent headache without postural features [3] as opposed to post-dural puncture headache [2, $3]$. It has been reported that patients may develop subdural haematoma before regeneration in haematopoietic stem cell transplantation when severe thrombocytopenia is a strong risk factor [7]. 
According to a recent systematic review, a platelet level of $40 \times 10^{9} / 1$ is considered 'safe' for LP, provided that the count is stable, that no concomitant antithrombotic therapy is given, that no other acquired or congenital coagulopathy is present and that the platelets are well functioning [6]. This concept may have a great impact since the rates of bleeding events have been shown to differ between haematologic diseases and the etiology of the thrombocytopenia [16]. Platelet counts below $40 \times 10^{9} / 1$ may also be safe, but there is insufficient data to make recommendations for such strategies. In case of platelet levels of $20-40 \times 10^{9} / 1$ in patients requiring LP, an individual decision based on an assessment of the risks and benefits is warranted [6].

A minimum 7-day pause of clopidogrel is often recommended because of considerable and irreversible platelet inhibition $[3,5]$. Dipyridamol and low-dose aspirin as a single therapy appear to have little impact on the bleeding risk and can thus be continued $[3,5,11]$. Only $6(55 \%)$ of the survey respondents adhered to the above, as the remaining 5 submitted having no routine pausation of antiplatelet drugs. However, this disparity should be viewed in the context of various aspects. First, as a routine measure, most haematology patients have already had their antithrombotic medication paused for several days prior to LP because of a pathological or cytotoxicity-induced nadir state. Secondly, the handling of haematopoietic stem cell transplants and acute leukemia is centralised to 5 haematology wards. Thus, considering the term 'routine practice', some perform LP on a daily basis while other departments have less than 25 LP annually [15]. Finally, LP is only contraindicated if the risk of the procedure outweighs the potential benefit. Given that the potential benefit might be higher in a leukemic patient, in whom postponement of the diagnosis and treatment may be detrimental - as opposed to elective surgery - one may argue that a greater risk may be accepted. Haematology patients for whom antiplatelet drugs have not been discontinued may still qualify for LP. Conversely, clopidogrel treatment, e.g. via a drug-eluting stent, can contraindicate a pause and thus suggests postponement of the LP in other settings [17].

An international normalised ratio (INR) limit of 1.5 is preferred, as reflected by our questionnaire and the literature $[3,5,11]$. However, this limit is arbitrary and no 'safe' INR threshold has yet been determined to guide clinical high-risk procedures such as LP, neurosurgery and liver biopsy $[3,5,11]$.

Para-clinical assessment of the risk of bleeding in patients with coagulopathy remains a challenge because of the poor predictive value of the available tests. Neither

Safety Measures before Lumbar Puncture in Denmark platelet counts nor activated partial thromboplastin times or INR [9] provide information about platelet function. TEG (e.g. TEG ${ }^{\circledR}$ or ROTEM ${ }^{\circledR}$ ) represents a whole-blood coagulation monitor that can be a useful tool to determine coagulation and fibrinolysis function and detect alterations in platelet aggregation [10]. PFA (e.g. PFA- $100^{\circledR}$ or Multiplate ${ }^{\circledR}$ ) is an alternative bedside assay of coagulation that specifically evaluates platelet function and may be superior in detecting platelet dysfunction in patients with a positive bleeding anamnesis. The information obtained from TEG or PFA could be used in conjunction with usual coagulation tests to determine if adequate coagulation is present before LP [9]. However, no available method has been able to provide high predictive values for bleeding risk [10].

TEG and PFA are not commonly used by Danish haematologists (table 1) despite their widespread availability on a national basis. Whether routine use of TEG and PFA will lead to an increase or a decrease in platelet transfusion and perhaps to fewer bleeding events remains to be determined.

Our survey showed that fundoscopy is not practiced before LP in the majority of haematology departments (table 1). Routine fundoscopy is disputed because it is difficult to perform or interpret and increased intracranial pressure may be present without papilledema [18]. Thus, a normal fundoscopy may lead to false reassurance [19]. In addition, increased intracranial pressure in itself will not lead to incarceration, except in certain circumstances where a pressure gradient has developed [3]. Current reviews and guidelines instead recommend a cranial computed tomography if a clinically significant increased intracranial pressure is suspected [3]. Which clinical signs should prompt a cranial computed tomography is currently being debated for the management of patients with suspected bacterial meningitis [20]. It is difficult to develop guidelines for use in haematological patients due to highly individual circumstances, but fundoscopy may be omitted in patients without symptoms of increased pressure.

There are limitations to this study. Firstly, as acknowledged, the majority of the respondents were senior staff members. This can imply a selection bias. Secondly, to limit the number of questions to the most common drugs, for which guidelines for cessation have been defined, we did not ask about the handling of novel, so-called direct, oral coagulation factor inhibitors such as dabigatran, rivaroxaban and apixaban.

In conclusion, this study shows considerable variation in the routine handling of antithrombotic medication 
and low platelet counts in patients before LP in Danish haematology departments. In general, practices adhere to current guidelines and the diversity may be explained by different opinions in the literature, especially on the platelet limit. There is a need for well-designed and highquality studies to establish an evidence-based approach to detect, guide and treat patients at risk of bleeding when in need of lumbar puncture. In addition, LP may be done routinely without fundoscopy.

\section{Acknowledgements}

The following professionals participated in the survey: Consultant Henrik Gregersen (Department of Haematology, Aalborg University Hospital), Consultant Carsten Helleberg (Department of Haematology, Copenhagen University Hospital Herlev), Prof. Jesper Stentoft (Department of Haematology, Aarhus University Hospital) Marie Toft-Petersen, MD (Medical Department, Viborg Holspital, and Department of Haematology, Aarhus University Hospital), Prof. Torben Plesner (University of Southern Denmark, Institute of Regional Health Science, and Department of Haematology, Section of Internal Medicine, Vejle Hospital), Consultant Jørn Starklint (Medical Department, Holstebro Holspital), Consultant Klas Raaschou-Jensen (Department of Haematology, Copenhagen University Hospital, Roskilde), Consultant Paul GramHansen (Department of Haematology, Odense University Hospital), and Consultant Torben Mourits-Andersen (Department of Haematology, Sydvestjysk Sygehus Esbjerg).

\section{Disclosure Statement}

The authors have no conflicts of interest to declare.

\section{References}

1 Lægemiddelstatistikregisteret. 2013. http:// www.medstat.dk (accessed June 3, 2013).

- 2 Arendt K, Demaerschalk BM, Wingerchuk DM, Camann W: Atraumatic lumbar puncture needles: after all these years, are we still missing the point? Neurologist 2009; 15:1720.

- 3 Wright BL, Lai JT, Sinclair AJ: Cerebrospinal fluid and lumbar puncture: a practical review. J Neurol 2012;259:1530-1545.

-4 Kreppel D, Antoniadis G, Seeling W: Spinal hematoma: a literature survey with metaanalysis of 613 patients. Neurosurg Rev 2003; 26:1-49.

5 Horlocker TT, Wedel DJ, Rowlingson JC, Enneking FK, Kopp SL, Benzon HT, Brown DL, Heit JA, Mulroy MF, Rosenquist RW, Tryba M, Yuan CS: Regional anesthesia in the patient receiving antithrombotic or thrombolytic therapy: American Society of Regional Anesthesia and Pain Medicine EvidenceBased Guidelines (Third Edition). Reg Anesth Pain Med 2010;35:64-101.

6 van Veen JJ, Nokes TJ, Makris M: The risk of spinal haematoma following neuraxial anaesthesia or lumbar puncture in thrombocytopenic individuals. Br J Haematol 2010;148:1525.

7 Kannan K, Koh LP, Linn YC: Subdural hematoma in two hematopoietic stem cell transplant patients with post-dural puncture headache and initially normal CT brain scan. Ann Hematol 2002;81:540-542.
8 Colosimo M, McCarthy N, Jayasinghe R, 13 Amorim JA, Remigio DS, Damazio Filho O, Morton J, Taylor K, Durrant S: Diagnosis and management of subdural haematoma complicating bone marrow transplantation. Bone Marrow Transplant 2000;25:549-552.

$\checkmark$ Chow L, Farber MK, Camann WR: Anesthesia in the pregnant patient with hematologic disorders. Hematol Oncol Clin North Am 2011;25:425-443, ix-x.

10 Afshari A, Wikkelso A, Brok J, Moller AM, Wetterslev J: Thrombelastography (TEG) or thromboelastometry (ROTEM) to monitor haemotherapy versus usual care in patients with massive transfusion. Cochrane Database Syst Rev 2011, p CD007871.

-11 Manchikanti L, Falco FJ, Benyamin RM, Caraway DL, Kaye AD, Helm S 2nd, Wargo BW, Hansen H, Parr AT, Singh V, Swicegood JR, Smith HS, Schultz DM, Malla Y, Hirsch JA: Assessment of bleeding risk of interventional techniques: a best evidence synthesis of practice patterns and perioperative management of anticoagulant and antithrombotic therapy. Pain Physician 2013;16:SE261SE318.

12 Davies JM, Murphy A, Smith M, O’Sullivan G: Subdural haematoma after dural puncture headache treated by epidural blood patch. $\mathrm{Br}$ J Anaesth 2001;86:720-723. de Barros MA, Carvalho VN, Valenca MM: Intracranial subdural hematoma post-spinal anesthesia: report of two cases and review of 33 cases in the literature. Rev Bras Anestesiol 2010;60:620-629, 344-629.

14 Janssens E, Aerssens P, Alliet P, Gillis P, Raes M: Post-dural puncture headaches in children: a literature review. Eur J Pediatr 2003; 162:117-121.

15 Moller A, Afshari A, Bjerrum OW: Diagnostic and therapeutic lumbar puncture performed safely and efficiently with a thin blunt needle. Dan Med J 2013;60:A4684.

16 Slichter SJ: Eliminate prophylactic platelet transfusions? N Engl J Med 2013;368:18371838.

17 Llau JV, Lopez-Forte C, Sapena L, Ferrandis R: Perioperative management of antiplatelet agents in noncardiac surgery. Eur J Anaesthesiol 2009;26:181-187.

18 Kastenbauer S, Winkler F, Pfister HW: Cranial CT before lumbar puncture in suspected meningitis. N Engl J Med 2002;346:12481251; author reply 1248-1251.

19 Korein J, Cravioto H, Leicach M: Reevaluation of lumbar puncture: a study of 129 patients with papilledema or intracranial hypertension. Neurology 1959;9:290-297.

20 Glimaker M, Lindquist L, Sjolin J: Lumbar puncture in adult bacterial meningitis: time to reconsider guidelines? BMJ 2013;346:f361. 